\title{
ADSORPTION OF HEAVY METAL BY NATURAL CLAYEY SOIL
}

\author{
Wawan Budianta* \\ Department of Geological Engineering, Gadjah Mada University, Yogyakarta, Indonesia
}

\begin{abstract}
This study focused on the capability of Clayey soil to retain and release heavy metals. Batch experiment for sample of clayey soil was conducted with several concentrated solutions of heavy metals. The results show that the clayey soil sample may have a relatively high heavy metal retention capacity. This is particularly positive in the context of municipal waste disposal (landfills) in Indonesia
\end{abstract}

Keywords: adsorption, heavy metal, clayey soil, batch experiment

\section{Introduction}

Unlike the concerns for radioactive waste disposal in the developed countries, the concerns about the increasing rate of solid waste production and the need for proper disposal and management to ensure sustainable environmental management and development has been the concerns of many developing countries like Indonesia. Hence the need for properly engineered sanitary landfill is imperative for a sustainable waste management and healthier environment, as the present common method of open dumping could expose the population to serious health hazards and the possible contamination of shallow groundwater system. However, a major constraint to the development of engineered landfills is the high cost of synthetic liners and its scarcity in the local markets, thus there is the need for other readily available

${ }^{*}$ Corresponding author: W. BUDIANTA, Department of Geological Engineering, Faculty of Engineering, Gadjah Mada University, Jl. Grafika 2 Yogyakarta, 55281, Indonesia. E-mail: wbudianta@ugm.ac.id source materials for landfill liner. The compatibility of a clay liner to a specific contaminant depends on its capacity to retard the migration of contaminants through sorption. Heavy metals, such as Lead $(\mathrm{Pb})$, Cooper $(\mathrm{Cu})$, Zinc $(\mathrm{Zn})$ and Cadmium (Cd) constitute one of the contaminant groups considered noxious to human health and are commonly found in several kinds of waste and landfill leachate. Hence, this study focuses on the assessment of sorption and engineering properties of clayey soil samples from Java, Indonesia for possible usage as a landfill liner or as a component of a landfill barrier system.

\section{Materials and methods}

Clayey soil samples were collected from Java, Indonesia. Several main properties of clayey soils were analyzed following standard procedures. Clayey soil pH was measured with a glass electrode at a 1:5 soil to water ratio. The particle size distribution was determined by the wet sieving and the pipette method. The cation exchange capacity (CEC) of soils was determined using $\mathrm{BaCl}_{2} \cdot 2 \mathrm{H}_{2} \mathrm{O}$ compulsive exchange method. The specific surface area was measured by using BET method. The mineralogical composition of clayey soil was performed using X-ray diffractometer. Clayey soil samples were air-dried and then an adsorption experiment was conducted. Adsorption experiment of heavy metals adsorption by clayey soil sample was determined using a batch equilibrium technique (Leitao and Zakharova, 2003). In the batch experiments the adsorptive behaviors of $\mathrm{Pb}, \mathrm{Cu}, \mathrm{Zn}$ and $\mathrm{Cd}$ have been studied 
for clayey soil sample. For this purpose, 10 gram of clayey soil has been put into $500 \mathrm{ml}$ poly-ethylene bottles. Then, $250 \mathrm{ml}$ of a solution containing four nitrate metals salt has been added into the bottle. The choice of the coion, $\mathrm{NO}_{3}^{-}$was based on the fact that $\mathrm{Cu}\left(\mathrm{NO}_{3}\right)_{2}$, $\mathrm{Cd}\left(\mathrm{NO}_{3}\right)_{4}, \mathrm{~Pb}\left(\mathrm{NO}_{3}\right)_{2}$ and $\mathrm{Zn}\left(\mathrm{NO}_{3}\right)_{2}$ are highly soluble in water. Moreover, $\mathrm{NO}_{3}$ is normally found in contaminated soils and groundwater. According to Reuss and Johnson (1986), the nitrate ion is not significantly adsorbed by soil solids and is highly mobile. The eight solution concentrations used were 5.0, 2.5, 1.25, 0.63, $0.32,0.16,0.08$ and $0.04 \mathrm{mmol} / 1$. The clayey soil suspension has been shaken for 12 hours at constant temperature and after left without shaking for additional 24 hours. The suspension was filtrated through a $45 \mu \mathrm{m}$ filter and the effluent was analyzed by using inductively coupled plasma-mass spectrometry (ICP-AES 7500; Shimadzu Corp., Kyoto, Japan) under optimal operating conditions. Analysis of heavy metals ion using ICP-AES is probably the most suitable detector used with success (Ebdon et al., 1986). All analyses were performed in three duplicate, and the results presented are the means of the three determinations. This procedure was repeated twice for each experiment. The adsorbed amount, Q, was calculated by

$$
Q=\frac{(V \cdot \triangle C)}{M}
$$

where,

$Q=$ adsorbed amount $(\mathrm{mg} / \mathrm{kg})$

$\triangle C=$ difference in metal concentration before and after experiment $(\mathrm{mg} / \mathrm{l})$

$V=$ volume of solution (l)

$M=$ mass of soil $(\mathrm{kg})$

In order to obtain a value for the maximum adsorption capacity $\left(Q_{\max }\right)$ for each solution, the procedure hereinafter described was used. The one-term Langmuir isotherm equation for adsorption can be written as follows (Appelo and Postma, 1996):

$Q=Q_{\max } \frac{K \cdot C}{1+K \cdot C}=Q_{\max } \frac{C}{\frac{1}{K}+C}=Q_{\max } \frac{C}{a+C}$

where,
$Q_{\max }=$ maximum adsorption capacity $(\mathrm{mg} / \mathrm{kg})$

$K=$ adsorption constant, $a=1 / K$

$C=$ initial metal concentration $(\mathrm{mg} / \mathrm{l})$

Then, by raising both members of the previous equation at -1 it is possible to obtain the following expression:

$$
\frac{1}{Q}=\frac{a+C}{Q_{\max } \cdot C}=\left(\frac{a}{Q_{\max }}\right) \cdot \frac{1}{C}+\frac{1}{Q_{\max }}
$$

Considering the axes $y=1 / Q$ and $x=1 / C$, it is possible to have a linear function of the type $y=d x+b$, where $d=a / Q_{\max }$ and $b=1 / Q_{\max }$. Then $1 / Q_{\max }$ is equal to the intercept of this straight line on the vertical axis, while $a / Q_{\max }$ is the slope of the straight-line equation. The correlation coefficient $\left(R^{2}\right)$ and $b$ and $\mathrm{d}$ values have been obtained from the linear equation. By this procedure Qmax and a have been derived for each solution in clayey soil sample. In the experiments carried out, described in the next section, the analyzed concentrations and the calculated experimental adsorbed amounts have been plotted in $a, C, Q$ graph together with the Langmuir adsorption values calculated with the previously obtained $Q_{\max }$ and $a$.

\section{Results and Discussion}

Several properties of this clayey soil sample are given in Table 1.

Several physical properties appear in Table 1 will influence the hydraulic conductivity performance of clayey soil sample as the liner, i.e. to be compacted to reach a minimum requirement of about $1 \times 10^{-9} \mathrm{~m} / \mathrm{s}$ or less. The acceptance criteria for the soil material for landfill liner should meet the following (Murray, et al., 1992):

1. Permeability of $1 \times 10^{-9} \mathrm{~m} / \mathrm{s}$

2. Minimum clay content of $10 \%$

3. Maximum gravel content of $30 \%$

4. Liquid limit not greater than $90 \%$ and plasticity index not greater than $65 \%$

Based on their physical properties in Table 1. one may conclude that the clayey soil sample is deemed suitable to be used as an engineered 
Table 1: Properties of clayey soil sample

\begin{tabular}{l|c}
\hline \multicolumn{1}{c|}{ Properties } & Sample \\
\hline Classification & Silty Loam \\
\hline Liquid Limit (\%) & 56.80 \\
\hline Plastic Limit (\%) & 23.31 \\
\hline Plasticity Index (\%) & 33.49 \\
\hline Liquidity Index (\%) & -0.04 \\
\hline Sand-Gravel (\%) & 22.9 \\
\hline Silt-Clay (\%) & 77.71 \\
\hline Hydraulic Conductivity & $8.5 \times 10^{-10} / \mathrm{s}$ \\
\hline pH & 7.2 \\
\hline Specific Surface Area $\left(\mathrm{m}^{2}\right)$ & 39.5 \\
\hline Specific Gravity & 2.63 \\
\hline Total Mineralogical & Quartz, Feldspar, Albite, \\
Composition & Kaolinite, Illite \\
\hline Clay Composition & Kaolinite, Illite, \\
& Monmorilonite \\
\hline Cation Exchange & 34 \\
Capacity (meq/100 g) & \\
\hline
\end{tabular}

clay liner because of their lower permeability, higher clay content and lower gravel content. The others properties also influence the attenuation capability of the soil to attenuate the movement of the contaminants. Others properties such as $\mathrm{pH}$ of the soils, cation exchange capacity (CEC), specific surface area (SSA), and clay mineralogy are important factors in the attenuation of the inorganic pollutant in leachate. All of these properties influence the attenuation of pollutants.

Table 1 shows that clayey soil sample has high soil $\mathrm{pH}$, and high CEC-SSA values. Samples that contain high values of these properties may influence the capability of the soil to attenuate the pollutants via various retention mechanisms. Therefore, this clayey soil sample has a potential in attenuating the contaminants leachate.

The main objective of the batch experiments was to obtain the value of $Q_{\max }$ for analyzed clayey soil. The eight solution concentrations have been used to calculate the $Q_{\max }$. Figure 1 to figure 4 present the linear relation between $1 / Q$ and $1 / C$ used to obtain the values of Langmuir constants (a) and $Q_{\max }$, accordingly to the described aforementioned procedure.

In Table 2 the obtained Langmuir equation constants, calculated using Equation 3, are pre-

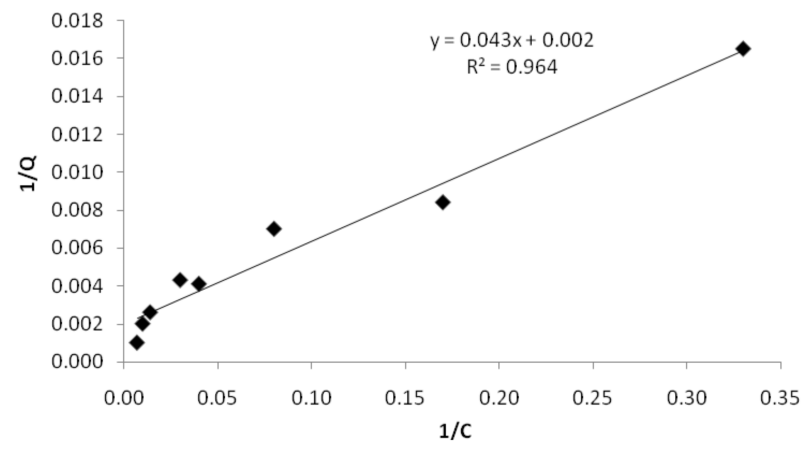

Figure 1: Linear relation between 1/Q and 1/C for $\mathrm{Cu}$

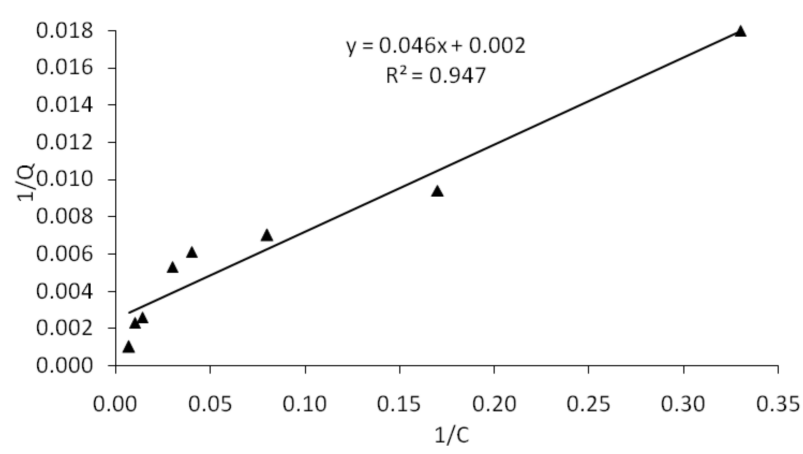

Figure 2: Linear relation between 1/Q and 1/C for $\mathrm{Pb}$

sented for the studied heavy metals and clayey soil (see Figure 1 to Figure 4 .

Table 2: Langmuir equation constants for several heavy metals

\begin{tabular}{c|c|c|c}
\hline Heavy Metal & $\mathbf{Q}_{\max }(\mathbf{m g} / \mathbf{k g})$ & $\mathbf{k}$ & $\mathbf{a}$ \\
\hline $\mathrm{Cu}$ & 500 & 0.046 & 21.8 \\
\hline $\mathrm{Pb}$ & 400 & 0.053 & 18.72 \\
\hline $\mathrm{Zn}$ & 109.89 & 0.194 & 5.14 \\
\hline $\mathrm{Cd}$ & 104.17 & 0.171 & 5.85 \\
\hline
\end{tabular}

Concerning the main question of the competitive adsorption mechanism, the batch experiment results have clearly shown a different behavior of heavy metals in the studied clayey soil sample. The sample was effective in adsorbing all the four metals and the amount of metal adsorbed varied in the following descending order: $\mathrm{Pb}>\mathrm{Cu}>\mathrm{Zn}>\mathrm{Cd}$. The chemisorption and the electronegativity are important factors in determining which of the heavy metals that would be preferentially adsorbed into the clay soil sample. The metals possessing higher elec- 


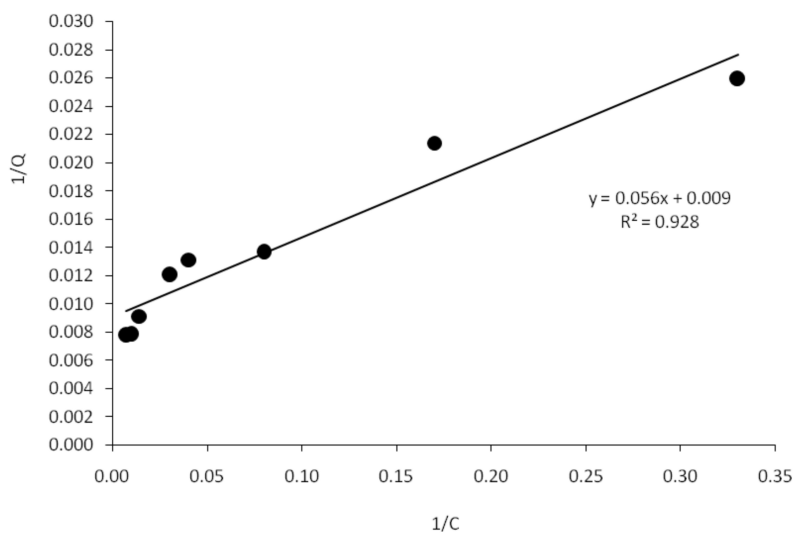

Figure 3: Linear relation between $1 / \mathrm{Q}$ and $1 / \mathrm{C}$ for $\mathrm{Zn}$

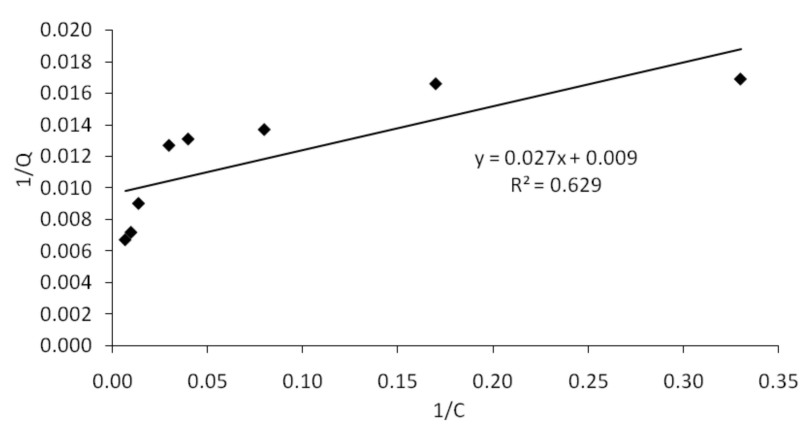

Figure 4: Linear relation between 1/Q and 1/C for $\mathrm{Cd}$

tronegativity should form the stronger covalent bond with the oxygen atoms on any particular mineral surface. In general, among the divalent metals, the predicted order of bonding preference was in the following order: $\mathrm{Pb}>\mathrm{Cu}>\mathrm{Zn}>$ Cd (Farrah and Pickering, 1977). Therefore, the concentrations of $\mathrm{Cu}$ and $\mathrm{Pb}$ adsorbed were obviously higher than $\mathrm{Zn}$ and $\mathrm{Cd}$, consistent with their relatively strong chemisorption on clays and oxides.

\section{Conclusion}

The properties of clayey soil sample used in this study suggest that permeability values well below the $1.0 \times 10^{-9} \mathrm{~m} / \mathrm{s}$ threshold (Table 1) and has a potential be used as liner landfill because of two main reasons; (1) the capability to be compacted to achieve lower permeability; and (2) better attenuation capability as suggested by the several properties of the soils (Table 1).

The buffering capacity, adsorption isotherms and maximum adsorption parameters from batch tests indicate that our clayey soil sample has high adsorption capacity on heavy metals. The study also concludes that there is a positive correlation between the maximum adsorption capacity and the basic properties of the soil samples. The best candidate of liner material must possess ideal physico-chemical properties and higher adsorption capacity. The study also suggests that physico-chemical properties and batch adsorption test can be very useful in the assessment of the best candidate for engineering liner material.

\section{References}

Appelo, A.J. and Postma, D. (1996) Geochemistry, Groundwater and Polution, A.A. Balkema Publishers, The Netherlands, $535 \mathrm{pp}$.

Ebdon, L, Steve Hill and Robert W. Ward (1986) Directly coupled chromatography-atomic spectroscopy, Analyst, Vol. 111, p.1113 - 1138

Farrah, H., and W. F. Pickering, W. F. (1977) Influence of clay-solute interactions on aqueous heavy metal ion levels, Water, Air, and Soil Pollution, Vol. 8, No.2, pp. 189-197

Murray, E.J., Rix D.W., Humprey, R.D (1992) Clay linings to landfill sites, Quaternary Journal of Engineering Geology, Vol. 25, pp.371-376

Griffin , R. A., Shimp, N. F., Steele, J.D., Ruch , R. R., White, W. A., and Hughes, G. M. (1976) Attenuation of pollutants in municipal landfill leachate by passage though clay, Environmental Science and Technology; Vol. 10, No. 13, pp 1262-1268

Reuss, J.O., and Johnson, D.W. (1986) Acid deposition and the acidification of soils and waters, Springer-Verlag, New York

Teresa E. Leitao and Tatiana Zakharova, (2003) Competitive Adsorption of Heavy Metals: Simulation in Laboratory Experiments, Seminario Sorbe Aguas Subterraneas, Lisboa, 27-28 February 